\title{
A New Scheme for Crack Growth Modeling by Coupling Modified Quarter Point Crack-Tip Element and the Level Set Method
}

\author{
Y Abdelaziz \\ LMS Laboratory, Department of Mechanical Engineering, University of Bechar, Algeria
}

Received 31 May 2011; accepted 8 December 2012

\begin{abstract}
In this paper, an efficient, numerical procedure is presented to track crack growth modeling without remeshing. The method's key feature is the coupling of a modified quarter-point crack tip element (MQPE) with the level set method (LSM) for crack growth problems. The LSM was used to represent the crack location, including the location of crack tips. The MQPE was used to compute the stress and displacement fields necessary for determining the rate of crack growth. Numerical test cases including various geometrical exceptions (the center-crack plate specimen, the single edge-crack plate specimen, and the double-edge crack plate) demonstrate the accuracy, robustness, and efficiency of the MQPE/LSM coupling. The extrapolation technique was used to estimate numerically the calibration factor for various specimens. This work confirms the feasibility of the MQPE/LSM to model accurately the singularity existing in the vicinity of the cracks. It allows an economic and adequate calculation of the stress intensity factors, which can be introduced into the various criteria of fracture or laws of propagation of the crack. The new method reduces the need for remeshing, and results agree well with reference data.
\end{abstract}

Keywords: Fracture, Crack, Singularity, SIFs, MQPE, Level set method, Calibration factors

$$
\begin{aligned}
& \text { مخطط جديد لنمو التشقق باستعمال النمذجة عن طريق ربط العناصر المنتهية المحسنة ذات الربع نقطة } \\
& \text { وبطريقة مجموعة المستوى } \\
& \text { يازيد عبدالعزيز } \\
& \text { الملخص: في هذه الورقة، نقدم طريقة رقمية فعالة لتتبع تطور التشقق دون الحاجة الى إعادة تشكيل الشبكة الرقمية. والفكرة الأساسية تكمن في }
\end{aligned}
$$

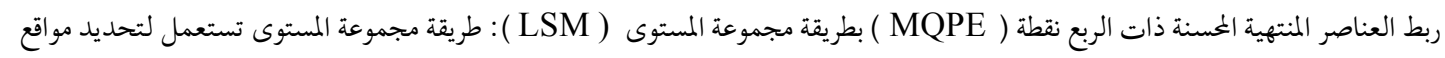

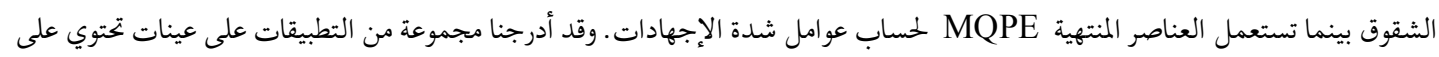

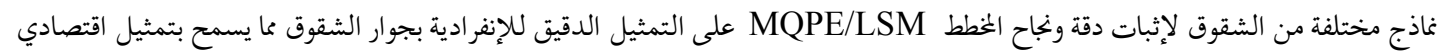

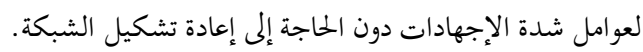

$$
\begin{aligned}
& \text { كلمات مفتاحية: الإنكسار، الشقوق، الإنفرادية، مجموعة المستوى، عوامل المعايرة. }
\end{aligned}
$$

$\overline{\text { *Corresponding author's e-mail: abdelaziz970@yahoo.fr }}$ 


\section{Introduction}

Computational mechanics is a flourishing subject in science and engineering. It is a field in which physical mechanics problems are solved through mechanics, computers, and various numerical methods. The finite element method (Long et al. 2009; Oñate 2009) has been recognized widely as a well-established numerical method as it has applications in virtually are areas of science and engineering. However, for fracture mechanics (Nestor 2004; Anderson 2005), one of the major difficulties in simulating crack problems numerically resides in the singular nature of the asymptotic crack tip fields. In order to capture this singularity using conventional finite element method, high mesh density in the crack front region is required. Also, there is a need for remeshing during crack growth simulations. However, this task is not always straightforward, especially for complex geometries.

Over last few decades, many approaches have been proposed to solve modeling of crack problems. For example, there have been methods based on the quarter-point finite element (Barsoum 1974), the enriched finite element method (Gifford and Hilton 1978), the boundary collocation method (Newman 1971), the integral equation method (Sneddon 1973), the body force method (Nisitani 1985), the boundary elements method (Cruse 1988), and the dislocation method (Chen and Hasebe 1995), plus mesh-free methods such as the element-free Galerkin method (Fleming et al. 1997). To avoid remeshing in modeling crack problems, diverse techniques were proposed, including the incorporation of a discontinuous mode on an element level (Oliver 1995), a moving mesh technique (Rashid 1998), and an enrichment technique based on a partition-of-unity X-FEM (Belytschko and Black1999).

Barsoum (1974) discovered that by taking the midside nodes of an element that are adjacent to a crack tip and moving them to the quarter point of the element side, the singular stress field which occurs at the crack tip could be produced (Fig. 1). Recently, various studies (Gray et al. 2003; Alashoaibi and Arifin 2006; Souiyah et.al. 2009; Abdelaziz 2010) were carried out to develop this type of element. These efforts are justified by the effectiveness of the quarter-point finite element to reproduce a singularity and by its simplicity of integration in major calculation programs without modifications. Specifically, Gray et al. (2003) proposed a modification of the finite element with a quarter of a point in the vicinity of the cracks and used this new type of element in the two-dimensional analysis of the fracture. The standard singular element was adjusted so that the near-tip crack opening displacement satisfied a known constraint: the coefficient of the term which is linear in the distance to the tip must vanish.

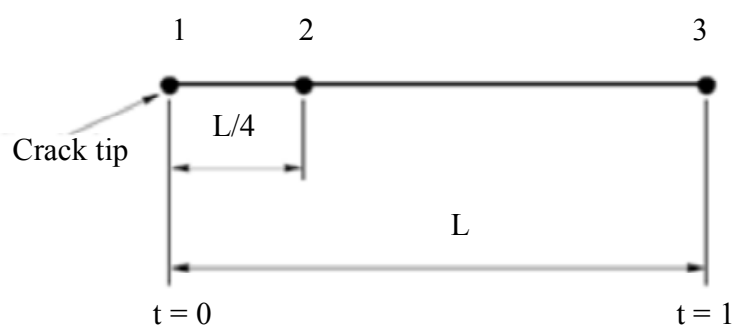

Figure 1. Standard quarter point finite element (QPE)

The two-dimensional standard quarter point finite element (QPE) is based upon the three-noded quadratic element. Fort $[0,1]$, the shape functions for this element are given by:

$$
\begin{aligned}
& \psi_{1}(t)=(1-t)(1-2 t) \\
& \psi_{2}(t)=4 t(1-t) \\
& \psi_{3}(t)=t(2 t-1)
\end{aligned}
$$

Gray et al. (2003) defined new shape functions (Fig. 2) by adding a cubic term:

$$
\begin{aligned}
& \hat{\psi}_{1}(t)=\Psi 1(t) \\
& \hat{\psi}_{2}(t)=4 t(1-t)-4 t(1-t)(1-2 t) / 3=-\frac{8}{3}\left(t^{3}-t\right) \\
& \hat{\psi}_{3}(t)=t(2 t-1)+2 t(1-t)(1-2 t) / 3=\frac{1}{3}\left(4 t^{3}-t\right)
\end{aligned}
$$

\section{Coupling the Level Set Method with Modified Quarter-Point Crack Tip Element (MQPE)}

The level set method (LSM) was developed by the American mathematicians (Osher and Sethian 1988). It has become popular in many disciplines, including image processing, computer graphics, computational geometry, optimization, and computational fluid dynamics. The aim of this technique is to track the motion of an interface by embedding the interface as the zero level set of the signed distance function. The motion of the interface is matched with the zero level set of the level set function, and the resulting initial value partial differential equation for the evolution of the level set function.

In this work, we propose a numerical scheme coupling the LSM with the Modified Quarter-Point Crack Tip Element. The LSM was used to represent the crack location including the location of crack tips. The MQPE was used to compute the stress and displacement fields necessary for determining the rate of crack growth.

A crack is described by two level sets (Fig. 3): 


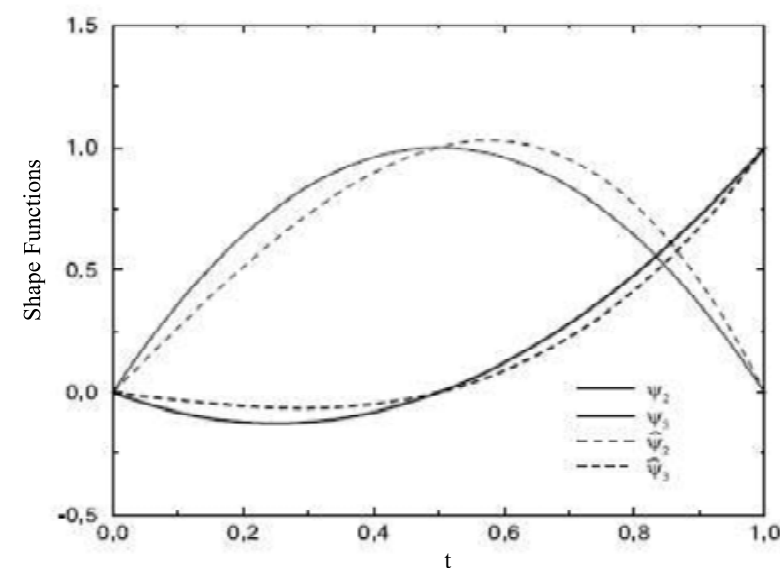

Figure 2. Standard $\left(\psi_{2}, \psi_{3}\right)$ and modified $\left(\hat{\psi}_{2}, \hat{\psi}_{3}\right)$ shape functions (Gray 2003)

1. a normal level set, $\psi(\mathrm{x})$, which the signed distance to the crack surface, and

2. a tangent level set $\phi(x)$, which is the signed distance to the plane including the crack front and perpendicular to the crack surface.

In a given element, $\psi_{\min }$ and $\psi_{\max }$ are, respectively, the minimum and maximum nodal values of $\psi$ on the nodes of that element. Similarly, let $\phi_{\min }$ and $\phi_{\max }$ be the minimum and maximum nodal values of $\phi$ on the nodes of an element, if $\phi_{\min } \phi_{\max }=0$ and $\psi_{\min }$ $\psi_{\max }=0$, the elements around the crack tip become degenerated finite elements.

\section{Numerical Examples}

In order to be able to compare our results with those in the literature, we determined the calibration factors of some samples of an isotropic material. Three physical problems were modeled using the MQPE/LSM approach. They are a center-crack plate (CCP) specimen, a single edge-crack plate (SECP) specimen, and a double-edge crack plate (DECP) specimen, as shown in Fig. 5. As these specimens had clean symmetry, we discounted their studies as a whole. Figure 6 describes the mesh and boundary conditions applied to the specimens. The analytical calibration is proposed:

$$
\mathrm{Y}(\mathrm{a} / \mathrm{w})=\frac{\mathrm{KI}}{\frac{\mathrm{F}}{\mathrm{Bw}} \sqrt{\pi \mathrm{a}}}
$$

where $K_{I}=$ stress intensity factor; $F=$ charge applied; $\mathrm{W}=$ width of the specimen; $B=$ thickness of the specimen; $a=$ length of the crack.

The general expression of stress intensity factors (SIFs) by means of the extrapolation technique is given by:

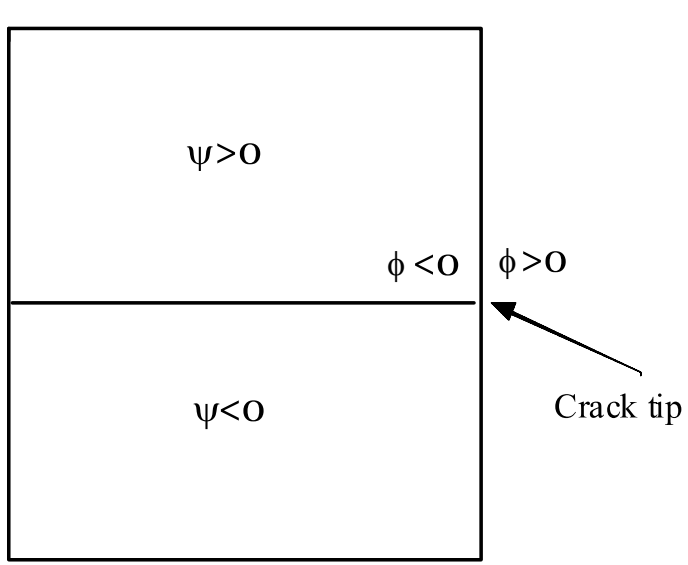

Figure 3. Construction of initial level set functions

$$
\mathrm{K}_{\mathrm{I}}=\frac{\mathrm{E} \sqrt{2 \pi}}{(\mathrm{k}+1)(1+v)} \frac{v}{\sqrt{\mathrm{r}}}
$$

where

$\mathrm{r}=$ outdistance face of the crack

$\mathrm{V}=$ transverse displacement

$\mathrm{E}=$ Young's modulus

For plane strain, $\mathrm{k}=(3-4 v)$

For plane stress, $\mathrm{k}=(3-v) /(1+v)$

$v=$ Poisson's ratio

The analytical calibration factor $\mathrm{Y}(\mathrm{a} / \mathrm{w})$ can be computed based on the equation in Tada's Handbook (2000) as follows:

(a) The CCP specimen

$\mathrm{Y}\left(\frac{\mathrm{a}}{\mathrm{w}}\right) \approx\left[1-0.025\left(\frac{\mathrm{a}}{\mathrm{w}}\right)^{2}+0.06\left(\frac{\mathrm{a}}{\mathrm{w}}\right)^{4}\right]\left[\cos \frac{\pi \mathrm{a}}{2 \mathrm{w}}\right]^{-\frac{1}{2}}$

(b) The SECP specimen

$$
\frac{\mathrm{Y}\left(\frac{\mathrm{a}}{\mathrm{w}}\right) \approx\left(\frac{2 \mathrm{w}}{\pi \mathrm{a}} \tan \frac{\pi \mathrm{a}}{2 \mathrm{w}}\right)^{\frac{1}{2}}}{0.752+2.02 \frac{\mathrm{a}}{\mathrm{w}}+0.37\left(1-\sin \frac{\pi \mathrm{a}}{2 \mathrm{w}}\right)^{3}}
$$

(c) The DECP specimen

$\mathrm{Y}\left(\frac{\mathrm{a}}{\mathrm{w}}\right) \approx\left[1+0.122 \cos ^{4}\left(\frac{\pi \mathrm{a}}{2 \mathrm{w}}\right)\right]\left[\frac{2 \mathrm{w}}{\pi \mathrm{a}} \tan \frac{\pi \mathrm{a}}{2 \mathrm{w}}\right]^{\frac{1}{2}}$

The results of this study are shown in Figs. 6-8 and are compared with those of the analytical solution (Tada and Paris 2000) (Table 1). The caliberation fac- 


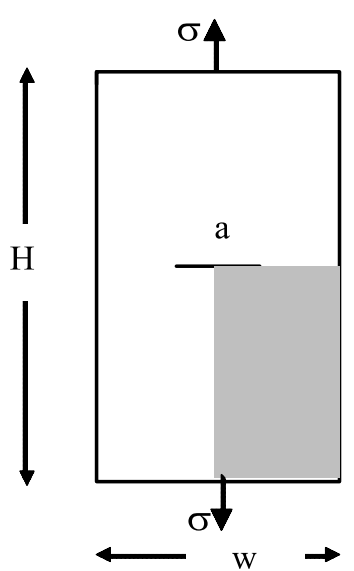

a) $\mathrm{CCP}$

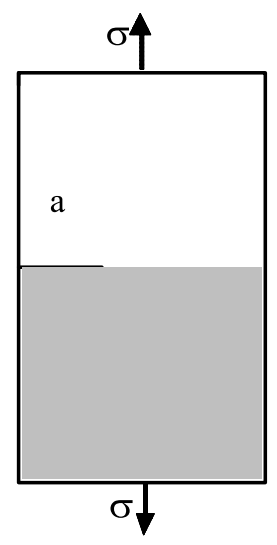

b) SECP

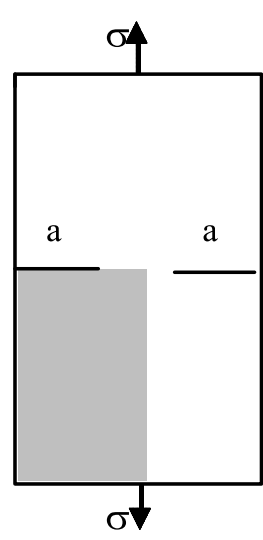

c) DECP

Figure 4. Various crack positions
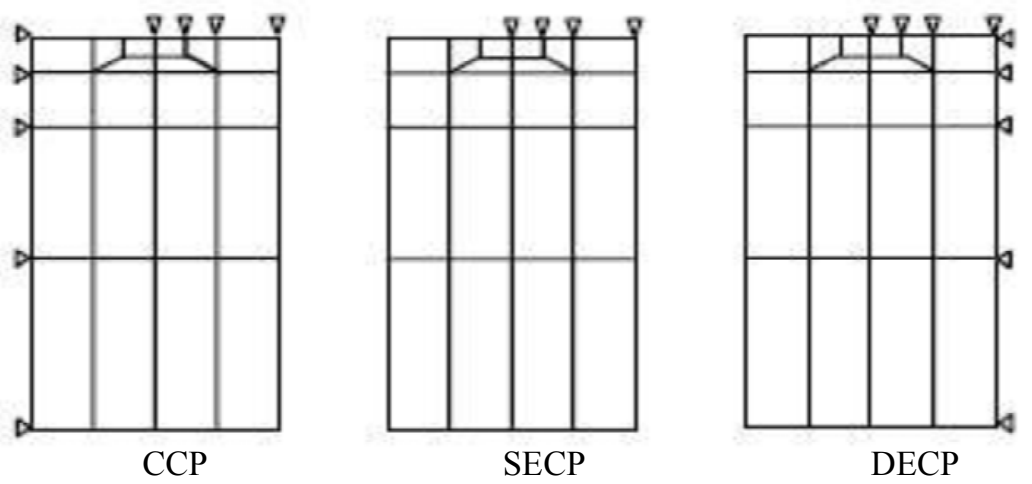

Figure 5. Mesh and boundary conditions

tor increases with an an increase in crack width. The results are in good agreement with analytical solution.

As can be seen from figures, the numerical study highlights the consistent agreement between current results obtained using MQPE/LSM approach, and the available analytical results. Besides the consistent agreement of results, it is necessary to emphasize two very important points:

* The MQPE was automatically introduced.

* The analysis was carried out without remeshing, and the initial mesh was maintained despite the change in the ratio $(\mathrm{a} / \mathrm{w})$.

\section{Conclusions}

Solving crack problems in fracture mechanics is imperative when quantifying and predicting the behavior of cracked structures under service conditions. To this end, the accurate evaluation of fracture parameters such as the stress intensity factors (SIF) is required. The finite element method has proved to be very well- suited for the study of fracture mechanics. However, one of its main drawbacks is that remeshing techniques are required to investigate and follow crack propagation patterns. Moreover, the crack tip singularity needs to be accurately represented using approximation methods. Due to the fact that the standard finite element methods are based on piecewise differentiable polynomial approximations, they are not well suited to problems with discontinuous and/or singular solutions. Typically, finite element methods require significant mesh refinement to get accurate results. In response to this deficiency, modified finite elements have been developed.

In this work, an initial attempt was made in developing a crack growth prediction tool under the assumption of linear elastic fracture mechanics. The tool was based upon the level set method, a MQPE crack-tip element, and the extrapolation technique for evaluating a calibration factor. The LSM was used to represent the crack location, including the location of crack tips. The MQPE was used to compute the stress and displacement fields necessary for determining the 


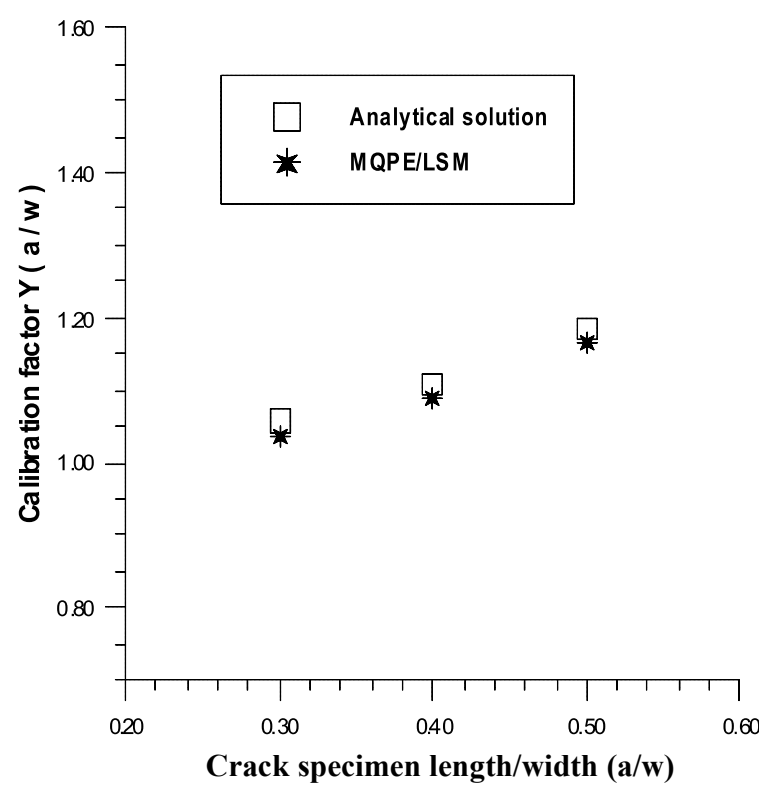

Figure 6. Calibration factor $\mathrm{Y}(\mathrm{a} / \mathrm{w})$ for $\mathrm{CCP}$ specimen

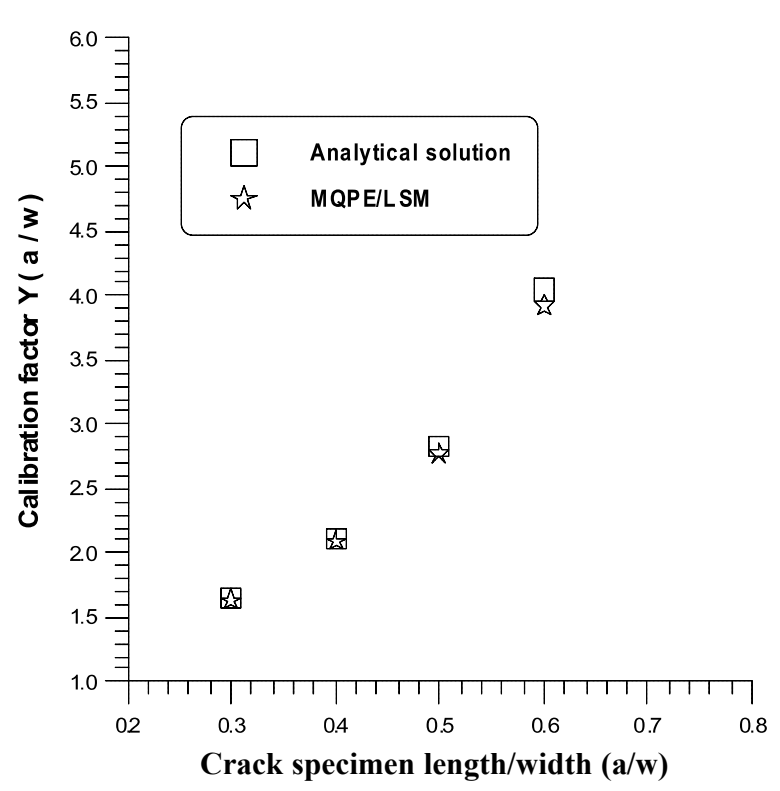

Figure 7. Calibration factor $\mathrm{Y}(\mathrm{a} / \mathrm{w})$ for SECP specimen

Table 1. Normalized factors

\begin{tabular}{ccccc}
\hline Specimen & $\mathbf{a} / \mathbf{w}$ & $\begin{array}{r}\text { Numerical Factor } \\
\mathbf{Y}_{\text {num }}\end{array}$ & $\begin{array}{c}\text { Analytical Factor } \\
\mathbf{Y}_{\text {th }}\end{array}$ & $\begin{array}{c}\text { Normalized Factor } \\
\mathbf{Y}_{\text {norm }}\end{array}$ \\
\hline \multirow{3}{*}{ CCP } & 0.3 & 1.035 & 1.058 & 0.978 \\
& 0.4 & 1.088 & 1.109 & 0.981 \\
& 0.5 & 1.166 & 1.186 & 0.983 \\
SECP & 0.3 & 1.633 & 1.655 & 0.987 \\
& 0.4 & 2.094 & 2.108 & 0.993 \\
& 0.5 & 2.774 & 2.826 & 0.982 \\
DECP & 0.6 & 3.920 & 4.044 & 0.969 \\
& 0.3 & 1.101 & 1.119 & 0.984 \\
& 0.4 & 1.118 & 1.131 & 0.988 \\
& 0.5 & 1.152 & 1.163 & 0.990 \\
& 0.6 & 1.216 & 1.226 & 0.992 \\
\hline
\end{tabular}

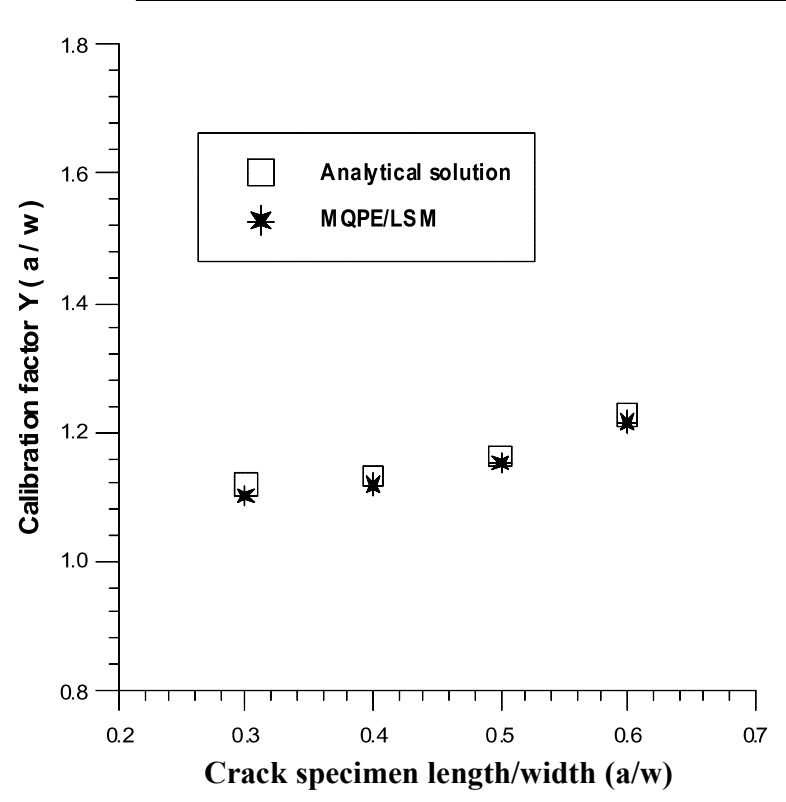

Figure 8. Calibration factor $\mathrm{Y}(\mathrm{a} / \mathrm{w})$ for DECP specimen rate of crack growth.

In this paper, the performance of this technique is illustrated and compared with existing solutions for three examples. The results obtained are compared to reported solutions and showed an excellent agreement.

This study has demonstrated the utility and potential of the MQPE elements as a computational fracture tool to study the singularity near the crack-tip. Moreover, MQPE coupled with LSM makes possible the accurate solution of engineering problems in complex domains, which may be difficult to solve using the standard finite element method.

\section{References}

Abdelaziz Y, Benkeira S, Rikioui T, Mekkaoui A (2010), A double degenerated finite element for modeling the crack tip singularity. Applied Mathematical Modeling 34:4031-39.

Alashoaibi A, Arifin K (2006), Finite element simulation of stress intensity factors in elastic-plastic 
crack growth. J Zhejiang Univ Sci. A:1336-42.

Anderson TL (2005), Fracture mechanics: Fundamentals and Applications. Boca Raton, Florida, USA, CRC Press.

Barsoum RS (1974), Application of quadratic isoparametric finite elements in linear fracture mechanics. Int J Fract. 10:603-5.

Belytschko T, Black T (1999), Elastic crack growth in finite elements with minimal remeshing. Int $\mathrm{J}$ Numer Meth Eng. 45:601-20.

Chen Y, Hasebe N (1995), New integration scheme for the branch crack problem. Eng Fract Mech. 52:791-801.

Cruse TA (1988), Boundary element analysis in computational fracture mechanics. Norwell, Massachusetts, Kluwer Academic Publishing.

Fleming M, Chu Y, Moran B, Belytschko T (1997), Enriched element-free Galerkin methods for crack tip fields. Int J Numer Methods Eng. 40:14831504.

Gifford J, Hilton P (1978), Stress intensity factors by enriched finite elements. Eng Fract Mech. 10:48596.

Gray L, Phan A, Paulino H, Kaplana T (2003), Improved quarter point crack tip element. Eng Fract Mech. 70:269-83.

Long Y, Cen S, Long Z (2009), Advanced finite element method in structural engineering. Wiesbaden, Germany, Springer Science + Business Media.

Nestor P (2004), Fracture Mechanics. Dordrecht, The Netherlands, Kluwer Academic Publishers.

Newman J (1971), An improved method of colloca- tion for the stress analysis of cracked plates with various shaped boundaries. Technical Report TN D-6376 NASA.

Nisitani H (1985), Body force method for determination of the stress intensity factors. J Aeronautical Soc India (Special Issue on Fracture Mechanics) 37:21-41.

Osher S, Sethian JA (1988), Fronts propagating with curvature-dependent speed : Algorithms based on Hamilton-Jacobi formulations. J Comput. Phys 79:12-49.

Oliver J (1995), Continuum modeling of strong discontinuities in solid mechanics using damage models. Comput Mech. 17:49-61.

Oñate E (2009), Structural analysis with the finite element method. Linear Statics: Vol. 1, Basis and Solids. Wiesbaden, Germany, Springer Science + Business Media.

Rashid M (1998), The arbitrary local mesh refinement method: an alternative to remeshing for crack propagation analysis. Comput Meth Appl Mech Eng. 154:133-50.

Sneddon I (1973), Integral transform methods, in: Methods of Analysis and Solutions of Crack Problems. Leyden, The Netherlands, Nordhoff International.

Souiyah M, Muchtar A, Alshoaibi A, Ariffin AK (2009), Finite element analysis of the crack propagation for solid materials. J App Sci 6:13961402.

Tada H, Paris P (2000), The stress analysis of cracks handbook. New York, USA, ASME Press. 